[Original]

\title{
Metrizamide Isopycnic Centrifugation for the Isolation of Macro- and Micronuclei from Paramecinm
}

\author{
Yukio Shiomi ${ }^{1}$, Toru HigashinakagawA2, Hidetoshi SaigA ${ }^{2}$ and Takashi Mita ${ }^{2 *}$ \\ ${ }^{1}$ Biology Division, National Cancer Center Research Institute. Tsukiji, Chuo-ku, Tokyo 104, Japan \\ ${ }^{2}$ Department of Molecular Biology, School of Medicine, University of Occupational and Environmental \\ Health, Japan. Kitakyushu 807, Japan
}

\begin{abstract}
A method for the large scale isolation and purification of macro- and micronuclei from Paramecium bursaria and $P$. trichium was developed, which included filtration with $\mathrm{Nu}$ clepore membrane for the separation of macro- and micronuclei and centrifugation in Metrizamide gradient for purification. Densities of macro- and micronuclei for both species were $\rho=1.2411-1.2516$ and $\rho=1.2089$, respectively, in the Metrizamide gradient. Isolated macronuclei retained RNA synthetic actvity in vitro, which was not affected by the treatment with Metrizamide.
\end{abstract}

Key words: Paramecium, macronucleus, micronucleus, nuclepore filtration, Metrizamide gradient.

(Received 17 May 1980)

\section{Introduction}

Ciliated protozoa are phylogenically interesting organisms and they contain in one cell two different sorts of nucleus. One is called macronucleus which functions for growth as it is a vegetative nucleus and the other micronucleus, because it is germinal nucleus, governs fertility in mating between strains.

Macronucleus is regenerated from micronucleus through the process of conjugation during which old macronucleus is disintegrated. Macronuclear anlage is derived from one of the syncaryons in exconjugants, which develops by repeated DNA synthesis endomitotically, forming so-called polyploid macronucleus.

Recently, we described the inequality in genomic organization between macro- and micronucleus of Tetrahymena (Iwamura et al., 1979). More than 20 times of preferential amplification of the single copy sequence of micronuclear DNA were observed and those sequences occupied 95\% of the total macronuclear genome. The highly repeated and the moderately repeated sequences remained virtually unamplified or were amplified to a much lesser extent. These findings indicate that the amplification of genes takes place not proportionately but unequally during macronuclear regeneration in conjugation. In addition, it was found that all classes of DNA sequences in micronuclear genome are represented in the population of cellular messenger RNA. Also more than $30 \%$ of such

*To whom request for reprint should be addressed. 
messenger RNAs are transcribed from the moderately repeated sequences which accounts only for a small percent of macronuclear DNA, suggesting the selective transcription of these sequences.

In Tetrahymena, it has been reported that macronuclear ribosomal RNA genes are linear double-stranded DNA with a palindromic structure. They are physically unlinked to the bulk DNA and packaged in a number of extrachromosomal nucleoli. In micronucleus, however, one copy of ribosomal RNA gene, which corresponds to half the palindrome, is integrated in micronuclear DNA (Gall, 1974; Karrer \& Ga1l, 1976; Engberg et al., 1976).

The evidence described above that micronuclear genomic organization is altered and reconstructed in regenerating macronucleus, will shed some light on the problems of celluar differentiation in higher organism.

It would be interesting to know whether the phenomenon mentioned above is common to other sorts of ciliates. It is quite important, however, to obtain micronuclear fraction in large amount and also in a highly purified state because contamination of micronuclei by only one macronucleus which corresponds to several tens of micronuclei on a DNA basis, would greatly reduce analytical reliability of micronuclear genomic composition. In this paper, we will describe a method newly developed for the isolation of macro- and micronuclei from Paramecium. We used P. bursaria and P. trichium because of their advantages, namely, large size of both types of nuclei and of relatively small micro-/macronuclear ratio. To obtain highly purified nuclear fractions, we introduced filtration through Nuclepore membrane for the separation of macro- and micronuclei and centrifugation in Metrizamide gradient for the purification.

\section{Materials and Methods}

\section{Cells and Culture}

P. bursaria and P. trichium, collected in fields and maintained routinely in the laboratory, are used in this study (both strains were generous gift from Prof. K. Hiwatashi, Faculty of Science, Tohoku University, Sendai). Both are symbiont chlorella-free strains. Solution A: $2 \mathrm{mM}$ phosphate buffer ( $\mathrm{pH} 7.5)-2 \mathrm{mM}$ citrate - lettuce juice $\left(1 \mathrm{~g} / 100 \mathrm{ml} \mathrm{H}_{2} \mathrm{O}\right.$ ). which was autoclaved for 20 min and concentrated $\mathrm{CaCl}_{2}$ was added to give a final concentration of $1.5 \mathrm{mM}$. Solution B: cultured Klebsiella aerogenes cells at a density of $10^{7}-10^{8} \mathrm{cell} / \mathrm{ml}$. Preculture was made by inoculating Paramecium stock into $15-20 \mathrm{ml}$ of pre-culture medium (Solution A mixed with an appropriate volume of Solution B). At a density of $10^{3} \mathrm{cell} / \mathrm{ml}$, the pre-culture was diluted $20-50$ fold to give a total volume of $500-5000 \mathrm{ml}$. Cells were incubated at $26^{\circ} \mathrm{C}$ until cell population density reaches $10^{4}$ cell $/ \mathrm{ml}$ (early stationary phase).

2. Isolation of nuclei

Concentrated $\mathrm{MgCl}_{2}$ was added to the cell culture to a final concentration of $10 \mathrm{mM}$. 
Cells were poured at a rate of $200 \mathrm{ml} / \mathrm{min}$ into a continuous rotor of 1 liter capacity (Tomy Seiko, Rotor No. 8, Tokyo) which contained 0.25 M sucrose-10 $\mathrm{mM} \mathrm{MgCl}_{2}-0.18 \%$ Nonidet P 40 (Shell Chemical Co. ) and was being spun at $10,000 \times \mathrm{g}$ at $4^{\circ} \mathrm{C}$. Cytoplasmic membranes were disrupted through the effect of nonionic detergent Nonidet $\mathrm{P} 40$, and the liberated macro- and micronuclei were both sedimented to the bottom of the rotor. The pellet of crude macro- and micronuclei was resuspended in $0.25 \mathrm{M}$ sucrose- $10 \mathrm{mM} \mathrm{MgCl}{ }_{2}$ and solid sucrose was added to this suspension to give a final concentration of $2.1 \mathrm{M}$. After sucrose was dissolved, this mixture was centrifuged at 20,000 rpm for $90 \mathrm{~min}$ in a Type 21 rotor of Beckman or Hitachi ultracentrifuge in order to remove contaminating cytoplasm. The pellet was resuspended in $0.25 \mathrm{M}$ sucrose $-10 \mathrm{mM} \mathrm{MgCl}_{2}$, centrifuged at $300 \times \mathrm{g}$ for $5 \mathrm{~min}$. The resulting pellet was resuspended in the same solution, overlayed onto $1.5 \mathrm{M}$ sucrose $-10 \mathrm{mM} \mathrm{MgCl}_{2}$ and centrifuged at $500 \times \mathrm{g}$ for $5 \mathrm{~min}$. The pellet constitutes the macronuclear fraction. Micronuclei were recovered from the supernatant by low speed centrifugation. A small amount of cross-contamination was observed between these two fractions at this stage. Micronuclear fraction was filtered through Nuclepore membrane filter ( $8 \mu \mathrm{m}$ pore size, $142 \mathrm{~mm}$ in diameter, Nuclepore Corporation, U.S.A.) to get rid of contaminating macronuclei. Micronuclei were then obtained by centrifuging the filtrate at $500 \times \mathrm{g}$ for $20 \mathrm{~min}$. In order to further purify macro- and micronuclei, each fraction was subjected to isopycnic centrifugation in Metrizamide (Nyegaard \& $\mathrm{Co} ., \mathrm{A} / \mathrm{S}$ ). The nuclear pellet was suspended in a small volume of $0.25 \mathrm{M}$ sucrose$10 \mathrm{mM} \mathrm{MgCl}$. Solid Metrizamide was added to this suspension to give a final concentration of $0.635 \mathrm{M}$, onto which a linear density gradient of $0.35-0.635 \mathrm{M}$ Metrizamide containing $10 \mathrm{mM} \mathrm{MgCl}_{2}$ was overlayed. The gradient was formed in a Beckman SW 41 tube and centrifuged at 25,000 rpm for $60 \mathrm{~min}$. Macro- and micronuclei floated up and deposited as a band at respective position. Macro- and micronuclei were each recovered from corresponding band region, and the buoyant density of each fraction was determined. Purified macro- and micronuclei were centrifuged down at $500 \times \mathrm{g}$ for $20 \mathrm{~min}$ after the density of each fraction was lowered by the addition of about 10 volumes of 0.25 M sucrose $-10 \mathrm{mM} \mathrm{MgCl}_{2}$. Isolated nuclei were immediately used or stored frozen at $-80^{\circ} \mathrm{C}$.

\section{Assay of DNA-dependent RNA polymerase activity}

RNA polymerase activity was assayed according to Higashinakagawa \& Mita (1972) and Higashinakagawa $e t$ al. (1975).

\section{Results and Discussion}

$P$. bursaria and $P$. trichium studied in this experiment contain in a cell one of each macro- and micronucleus with a significantly large volume. This feature was considered to be suited to analyze the genomic organization of each nucleus. If the approximate size of each nucleus is expressed in terms of short axis $\times$ long axis of the nucleus, the size 
is $5 \mu \mathrm{m} \times 7.5 \mu \mathrm{m}$ for micronucleus and $15 \mu \mathrm{m} \times 30 \mu \mathrm{m}$ for macronucleus. These values are compared to those of Tetrahymena; $2.5 \mu \mathrm{m} \times 2.5 \mu \mathrm{m}$ for micronucleus and $10 \mu \mathrm{m} \times 10$ $\mu \mathrm{m}$ for macronucleus, suggesting the larger content of genetic material in Paramecium species studied here.

The purpose of this study was to explore a way to isolate macro- and micronulear fraction in a highly purified state. In contrast to the case in Tetrahymena, the method for sterile cultivation has not been developed for Paramecium except for P. aurelia. Therefore the first problem encountered was how to remove the contaminating material such as lettuce juice or $K$. aerogenes cells, during the course of nuclear isolation. Secondly, it was crucial to reduce the cross-contamination between the two nuclear fractions, thus resulting in a highly purified nuclear preparation. For example, the contamination of the micronuclear fraction by only one macronucleus corresponds to about 30 micronuclei on a DNA basis. Other points to be paid attention to were morphological integrity of the isolated nuclei as compared to those in situ and the retention of physiological activities. In the course of exploring the isolation procedure, special care was paid to these points. The large contaminating particulates which were formed in the culture medium as cells grow were collected to the tapered bottom of the culture vessel. The amount of $K$. aerogenes to be added was controlled so as to be consumed up by the late logarithmic or early stationary phase. Prior to the isolation of nuclei, the supernatant of the culture was transferred to another vessel leaving the large particulates and $1 \mathrm{M} \mathrm{MgCl}_{2}$ was added to the supernatant to give a final concentration of $10 \mathrm{mM}$. For the rapid nuclear isolation from large scale culture as much as 10 liter continuous centrifugation is recommended. Nuclei are released from the cells during centrifugation through the effect of nonionic detergent Nonidet P 40 contained in the medium and they are sedimented to the bottom of the rotor. Nuclei were further purified by the centrifugation through 2.1 M sucrose$10 \mathrm{mM} \mathrm{MgCl}{ }_{2}$. Macronuclear fraction without contamination of micronuclei can easily be obtained by subjecting the nuclear fraction to low speed centrifugation through $1.5 \mathrm{M}$ sucrose $-10 \mathrm{mM} \mathrm{MgCl}$. Pure micronuclei can be obtained by the filtration of nuclear fraction through Nuclepore membrane. The pore is made by neutron irradiation and is uniformly-sized. In the present studies, the membrane of $8 \mu \mathrm{m}$ pore-size was used which allows micro- but not macronuclei to pass through. Thus micronuclei without macronuclear contamination could be obtained. At this stage, however, some small contaminating particulates were found in both the macro- and micronuclear fractions. For further purification of macro- and micronuclei, isopycnic centrifugation in Metrizamide was performed. Metrizamide is a chemically stable glucose derivative and has advantage over sucrose or glycerol in that its aqueous solution can reach high density while the viscocity remains relatively low. This substance has so far been used for the fractionation of nucleoprotein (chromatin). It has been known that buoyant density in a Metrizamide solution of DNA and RNA is $1.12-1.16$ and 1.17, respectively, while protein has a higher buoyant density of 1.5. Thus the buoyant density of the chromatin depends on its protein/nucleic acids ratio (Rickwood et al., 1973; Wray, 1976). It has been 

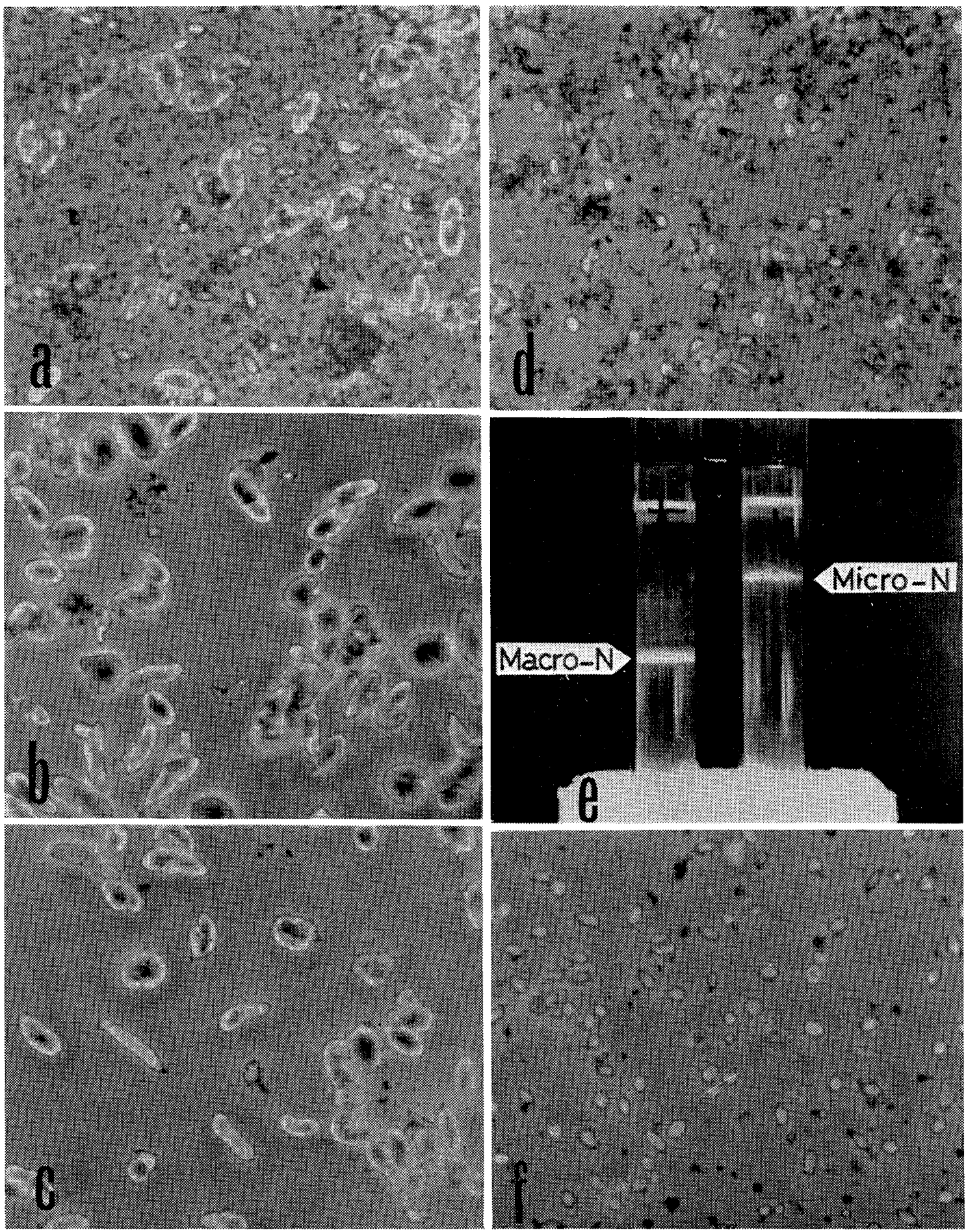

Fig. 1. Photomicrographs of macro- and micronuclei of Paramecium bursaria during the course of isolation.

a) Nuclear fraction from 2.1 $\mathrm{M}$ sucrose centrifugation.

b) Macronuclei from $1.5 \mathrm{M}$ sucrose sedimentation.

c) Macronuclei from Metrizamide gradient.

d) Micronuclei from Nuclepore membrane filtration.

e) Macro- and micronuclear bands in Metrizamide gradient.

Macro-N: Macronuclei, Micro-N: Micronuclei.

f) Micronuclei from Metrizamide gradient. Magnification, $1200 \times$. 
shown from the experiment with catalase that Metrizamide has no significant effect on enzyme activity (Birnie et al., 1973).

Several procedures of centrifugation in Metrizamide were tried and the best separation was obtained when the respective nuclear fraction was placed at the bottom of the tube allowing the nuclei to float up through the Metrizamide gradient during centrifugation. If the nuclei were layered on the top or at the middle of the Metrizamide gradient, or they were dispersed throughout the gradient, the separation was not as good. An attempt to separate macro- and micronuclei in one Metrizamide gradient was unsccessful since the separation of the two kind of nuclei was incomplete.

The buoyant density $(\rho)$ of macro- and micronuclei were obtained from the equation:

$$
\rho=3.350 \mathrm{C}-3.462
$$

where $\mathrm{C}$ is the refractive index of the fraction where respective nuclei banded. For both $P$. bursaria and $P$. trichium buoyant density was $1.2411-1.2516 \mathrm{~g} / \mathrm{cm}^{3}$ for macronuclei and $1.2089 \mathrm{~g} / \mathrm{cm}^{3}$ for micronuclei, respectively.

The difference in the buoyant densities may be due to the difference in the protein/DNA ratio between macro- and micronuclei.

The contaminants floated up to the top or sedimented down to the bottom of the tube but never found in the region where respective nuclei deposited. Thus the macro- and micronuclei were obtained in a highly purified state. The morphology of the nuclei in the course of the isolation is shown in Fig. 1.

The activity of DNA-dependent RNA polymerase of macronuclei was compared before and after centrifugation in Metrizamide. As shown in Table 1, no significant effect of Metrizamide on RNA synthetic activity was observed. Table 1 also shows that RNA synthetic activity of the nuclear preparation is not affected by rifampicin. Thus it can be concluded that $K$. aerogenes is completely removed during the course of nuclear isolation.

The procedure for the isolation of nuclei from Paramecium aurelia has been described

Table 1. In vitro RNA synthesis in isolated macronuclei of Paramecium bursaria

\begin{tabular}{|c|c|}
\hline Metrizamide & ${ }^{14} \mathrm{C}$-UMP incorporated $/ 100 \mu \mathrm{g} \mathrm{DNA}^{11}$ \\
\hline non-treated & $4,890 \mathrm{cpm}$ \\
\hline+ Rifampicin ${ }^{2)}$ & 5,250 \\
\hline treated & 4,770 \\
\hline+ Rifampicin & 5,160 \\
\hline$K$. aerogenes $^{3)}$ & 825 \\
\hline+ Rifampicin & 558 \\
\hline
\end{tabular}

1) Incubations were carried out at $28^{\circ} \mathrm{C}$ for $30 \mathrm{~min}$.

2) Rifampicin added was $25 \mu \mathrm{g} /$ assay.

3) Baceria used were $8 \times 10^{9}$ cells in $150 \mu l /$ assay. 
by Cummings \& Tait (1975). However, the method gave incomplete separation of macro- and micronuclei. The present procedure involving the use of Nuclepore membrane filter and Metrizamide gradient centrifugation is a much more advantageous method over the previously developed procedure with respect to high purity and yield and its applicability to large scale isolation.

\section{Acknowledgement}

This work was supported in part by rearch grants from the Ministry of Labor and from the Naito Foundation and from the Ministry of Education, Science and Culture, Japan.

\section{References}

Birnie, G.D., Rickwood, D. \& Hell, A. (1973): Buoyant densities and hydration of nucleic acids, proteins and nucleoprotein complexes in Metrizamide. Biochim. Biophys. Acta, 331: 283-294.

Cummings, D. J. \& Tait, A. (1975): The isolation of nuclei from Paramecium aurelia. In: Methods in Cell Biology, IX. (Prescott, D. M., ed.). Academic Press, N. Y. pp. 281-310.

Engberg, J., Andersson, P., Leick, V. et al. (1976): Free ribosomal DNA molecules from Tetrahy. mena pyriformis GL are giant palindromes. J. Mol. Biol., 104: 455-470.

Gall, J. G. (1974): Free ribosomal RNA genes in the macronucleus of Tetrahymena. Proc. Nat1. Acad. Sci., 71: 3078-3081.

Higashinakagawa, T. \& Mita, T. (1972): Novel features of DNA-dependent RNA polymerase from protozoan Tetrahymena pyriformis. FEBS Letters, 25: 73-76.

Higashinakagawa, T., Tashiro, F. \& Mita, T. (1975): DNA-dependent RNA polymerase from a protozon, Tetrahymena pyriformis. I. Extraction and partial characterization. J. Biochem., 77: 783-793.

Iwamura, Y., Sakai, M., Mita, T. et al. (1979): Unequal gene amplification and transcription in the macronucleus of Tetrahymena pyriformis. Biochemistry, 24: 5289-5294.

Karrer, K. M. \& Gall, J. G. (1976): The macronuclear ribosomal DNA of Tetrahymena pyriformis is a palindrome. J. Mol. Biol., 104: 421-454.

Rickwood, D., Hell, A. \& Birnie, G. D. (1973): Isopycnic centrifugation of sheared chromatin in metrizamide gradients. FEBS Letters, 33: 221-224.

Wray, W. (1976): Isopycnic centrifugation of mammalian metaphase chromosomes in Metrizamide. FEBS Letters, 67: 202-207. 
Paramecium 大核と小核分離のための Metrizamide Isopycnic Banding 法

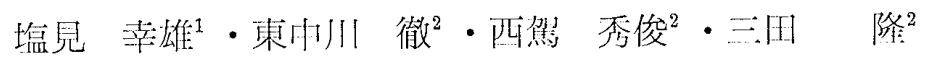

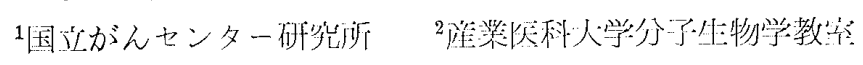

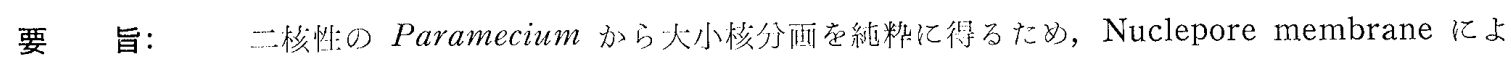
る filtration と Metrizamide による isopycnic banding centrifugation を組み合せ

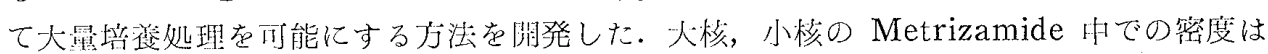
異なり，それぞれ $\rho=1.2411-1.2516 \mathrm{~g} / \mathrm{cm}^{3}, \rho=1.2089 \mathrm{~g} / \mathrm{cm}^{3}$ であった。辈離された

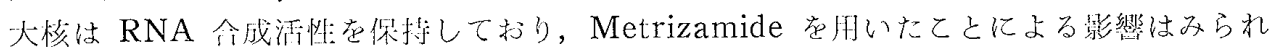
なかった。

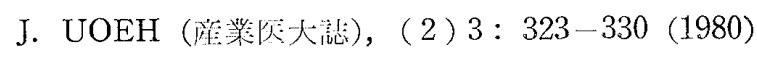

